\title{
What can we learn from California Institute for Regenerative Medicine's first 50 clinical trials?
}

\author{
Audrey R Chapman*,1 \\ ${ }^{1}$ Healey Professor of Medical Ethics \& Humanities, Department of Community Medicine \& Health Care, UConn School of \\ Medicine, Affiliate, Institute for Systems Genomics, 263 Farmington Ave Farmington, CT 06002, USA \\ *Author for correspondence: Tel.: +1 860679 1590; achapman@uchc.edu
}

First draft submitted: 18 January 2018; Accepted for publication: 19 September 2019; Published online: 4 October 2019

Keywords: California Institute for Regenerative Medicine • clinical trials $\bullet$ CIRM $\bullet$ embryonic stem cells $\bullet$ first-inhuman clinical trials • pluripotent stem cells

In 2004, California voters approved Proposition 71 [1], the California Stem Cell Research and Cures Initiative, which authorized US $\$ 3$ billion to fund stem cell research. Proponents had advocated for the measure to have the resources to speed the delivery of stem cell treatments and cures to patients with unmet medical needs, especially to fund embryonic stem cell research, which was not receiving sufficient federal funding. The California Institute for Regenerative Medicine (CIRM) was established to administer the funds. CIRM has used the bond funds to make grants and loans to researchers, institutions and companies in California for basic research, training programs, the development of infrastructure and the support of clinical trials. This funding has launched California into the top ranks of stem cell science. CIRM currently has some 300 active stem cell programs in its portfolio and CIRM's funded researchers have published over 3000 articles in scientific journals [2].

Around a fifth of CIRM's expenditures to date, US $\$ 647$ million as of January 2019 , has been devoted to supporting clinical trials, part of CIRM's rapidly expanding translational portfolio [3]. Most of these grants and loans were made in the past 3 years. A total of 33 trials were added between 2015 and 2018 and US $\$ 100.5$ million invested in 2018 alone [4], as CIRM sought to accelerate the testing of candidate stem cell therapies in advance of returning to the voters in 2020 for a US $\$ 5$ billion renewal of funding. The investment in the clinical trials necessary for the US FDA's authorization to market the therapy reflects CIRM's realization that testing cell-based therapies is far more complex than chemically based small molecule drugs and that the high costs associated with the trials are beyond the resources of the academic medical centers and small biopharmaceutical companies engaging in stem cell research [4]. Moreover, the complexity of testing candidate stem cell-based biologics increases the uncertainties and risks inherent in early clinical trials, especially since most of these therapies are first-in-human clinical trials.

In May 2011, CIRM funded its first clinical trial, which was also the first-in-human testing of a therapy developed from human embryonic stem cells. Some 7.5 years later, in December 2018, CIRM's Board approved funding for its 50th clinical trial [5]. This article analyses those 50 clinical trials to assess CIRM's priorities. In view of the central role of CIRM in the pluripotent stem cell field, the profile of the trials also affords an opportunity to assess progress in the stem cell field.

\section{Profile of CIRM's first 50 clinical trials}

CIRM's initial 50 clinical trials covered 10 different disease areas [3]. The greatest number of trials was for candidate therapies for blood cancers, other blood diseases and solid cancers. Together, these three categories represent slightly more than half of all of CIRM's assisted clinical trials. The distribution of the disease areas of the 50 clinical trials is as follows: blood cancers 19\%, other blood diseases $19 \%$, solid cancers $14 \%$, neurological applications $12 \%$, kidney disorders $8 \%$, diabetes, heart diseases, eye disorders and HIV-AIDS each $6 \%$ and bone diseases $4 \%$ [2]. Table 1 provides an overview of CIRM's first 50 trials, detailing the institution to which the grant was made, the disease area, cell type of interest and the trial phase. 


\begin{tabular}{|c|c|c|c|}
\hline Investigating organization & Disease area & Type of cell & Phase \\
\hline University of Southern California (CA, USA) & AMD & hESC & 1 \\
\hline University of California, San Francisco (CA, USA) & Alpha thalassemia major & $\mathrm{HSCS}$ & 1 \\
\hline BrainStorm Cell Therapeutics (NY, USA) & ALS & MSCs & III \\
\hline Cedars-Sinai Medical Center (CA, USA) & ALS & Genetically engineered adult stem cell & $1 / 11$ \\
\hline UCSD & B cell cancers, leukemia & Monoclonal antibodies & $1 / 11$ \\
\hline Stanford University (CA, USA) & B cell cancers, leukemia & Adult CAR-T cell therapy & 1 \\
\hline Sangamo BioSciences (CA, USA) & Beta thalassemia & Engineered blood cells & $1 / I I$ \\
\hline University of California, San Diego (CA, USA) & Blood cancer & Antibody & 1 \\
\hline Stanford University & Blood cancer, solid tumors & Antibody & 1 \\
\hline Angoicrine Bioscience (CA, USA) & Blood cancer & Engineered T cells & 1 \\
\hline ImmunoCellular Therapeutics (CA, USA) & Brain cancer & Immune cells & III \\
\hline Beckman Research Institute at City of Hope (CA, USA) & Brain cancer & CAR T cells & 1 \\
\hline Forty Seven, Inc. (CA, USA) & Colon cancer & Antibody & $1 / 11$ \\
\hline Capricor Therapeutics (CA, USA) & Heart disease & Donor heart cells & ॥ \\
\hline Capricor Therapeutics & Heart failure & Heart cells & II \\
\hline University of California, Davis (CA, USA) & HIV-related lymphoma & HSCs & $1 / 11$ \\
\hline Calimmune, Inc. (CA, USA) & HIV/AIDS & Genetically modified bone marrow cells & $1 / I I$ \\
\hline Beckman Research Institute at City of Hope (CA, USA) & HIV/AIDS & Genetically modified blood cells & 1 \\
\hline University of California, Davis & Huntington's disease & Engineered MSCs & $1 / 11$ \\
\hline Stanford University & Kidney failure & T cells & 1 \\
\hline Humacyte (NC, USA) & Kidney failure & Donor adult cells & III \\
\hline Stanford University & Kidney failure & Blood stem cells, T cells & 1 \\
\hline Humacyte (NC, USA) & Kidney failure & Donor adult stem cells & III \\
\hline Medeor Therpeutics, Inc. (CA, USA) & Kidney failure & Donor blood forming cells & III \\
\hline Nohla Therapeutics, Inc. (WA, USA) & Leukemia & HSC stem cells & ॥ \\
\hline Forty Seven, Inc. (CA, USA) & Leukemia & Monoclonal antibodies & 1 \\
\hline University of California, Los Angeles (CA, USA) & Lung cancer & Gene-modified dendritic cells & 1 \\
\hline Caladrius Biosciences (NJ, USA) & Melanoma & Patients own tumor cells & III \\
\hline University of California, Los Angeles & Melanoma skin cancer & Gene edited immune cells & 1 \\
\hline Poseida Therapeutics (CA, USA) & Multiple myeloma & CAR-T modified T stem cells & 1 \\
\hline Calibr (CA, USA) & Osteoarthritis & Adult KA34 stem cells & 1 \\
\hline University of California, Davis & Osteonecrosis & MSCs & $1 / 11$ \\
\hline Cedars-Sinai Medical Center & Pulminary hypertension & Donor heart cells & $1 / 11$ \\
\hline University of California, Irvine (CA, USA) & Retinitis pigmentosa & Retinal progenitor cells & $1 / 11$ \\
\hline JCyte (CA, USA) & Retinitis pigmentosa & Retinal progenitor cells & $1 / 11$ \\
\hline University of California, San Francisco & ART-SCID & Genetically modified blood cells & I \\
\hline St Jude Children's Research Hospital (TN, USA) & X-SCID & Gene therapy & $1 / 11$ \\
\hline Stanford University & X-SCID & Monoclonal antibody & $1 / 11$ \\
\hline University of California, Los Angeles & Sickle cell disease & Genetically modified blood stem cells & 1 \\
\hline Beckman Research Institute at City of Hope (CA, USA) & Sickle cell disease & Donor blood cells & 1 \\
\hline Geron Corp (CA, USA) & Spinal cord injury & hESCS & 1 \\
\hline Asterias Biotherapeutics (CA, USA) & Spinal cord injury & hESCS & $1 / 11$ \\
\hline SanBio, Inc. (CA, USA) & Stroke & Modified MSCs & ॥ \\
\hline Caladrius Biosciences (NJ, USA) & Type 1 diabetes & Modified T cells & ॥ \\
\hline ViaCyte, Inc. (CA, USA) & Type 1 diabetes & hESCS & $1 / 11$ \\
\hline ViaCyte, Inc. & Type 1 diabetes & hESCs & $1 / I I$ \\
\hline University of California, Los Angeles & X-linked chronic granulomatous & Genetically modified blood cells & $1 / 11$ \\
\hline San Bio, Inc. (CA, USA) & Stroke & Modified MSCs & II \\
\hline
\end{tabular}


As might be expected, the majority of these 50 clinical trials are early phase trials, primarily Phase I trials designed to evaluate tolerability and safety and not to assess efficacy as later stage trials do. Of the 50 CIRM supported trials, 36 are either Phase I or Phase I/II, which are trials that can integrate the planning and transition from Phase I to Phase II. Most of the CIRM-supported Phase I trials are designed to enroll small numbers of participants, ranging from 6 to 18 patients, but there are a few trials with as many as 57, 112 or even 156 patients targeted. A few of CIRM's supported trials have progressed to Phase II and four have begun Phase III recruiting. These latter trials are the BrainStorm Cell Therapeutics (NY, USA) trial for amyotrophic lateral sclerosis, Medeor Therapeutics (CA, USA) trial for kidney disease and one of Humacyte's (NC, USA) two candidate therapies for kidney failure.

Two Phase III trials have been closed. Caladrius Biosciences (NJ, USA) terminated testing during a Phase III trial for an experimental therapy for melanoma skin cancer, ostensibly for business reasons. Also, ImmunoCellular Therapeutics (CA, USA) suspended its Phase III trial of a therapeutic for glioblastoma brain cancer, reportedly for lack of financial reasons. Because Phase III trials have to enroll a greater number of patients than earlier phases, they are much more expensive. Many investigational products flounder at this stage, sometimes described as the 'valley of death', because of the financial expense and because of the difficulty of enrolling a sufficient number of patients. Even if CIRM receives a second round of funding by the voters, it will lack the resources to fully underwrite Phase III of the clinical trials it has previously supported and will need a partnership from other funders.

CIRM has invested in stem cell work conducted both by academic institutions and small biotechnology companies in California. Although 91\% of all CIRM's funding to date has been allocated to academic institutions [7], a substantial number of the CIRM-supported clinical trials are being conducted by small biotechnology companies. CIRM has made grants or loans to 16 such companies to conduct stem cell clinical trials and six of these companies have received CIRM support to conduct two clinical trials.

Although the campaign for Proposition 71 stressed the need to have public funding to develop therapeutics from human embryonic stem cells, only five of the clinical trials CIRM has supported to date have tested candidate therapies derived from human embryonic stem cells. None of the CIRM supported clinical trials are as yet evaluating candidate therapies developed from human induced pluripotent stem cells which were first developed after the referendum.

The first clinical trial CIRM funded in 2011 was Geron Corporation's Phase I trial to assess GRNOPC1, a human embryonic stem cell-derived candidate therapy for treatment of severe spinal cord injuries. However, after five patients were injected, apparently without any suffering serious adverse effects or evidence of immune rejection of GRNOPC1 even after the withdrawal of the immunosuppresive drug, Geron halted the trial. In a statement, the company claimed its decision was motivated by capital scarcity and uncertain economic conditions and not the lack of promise of stem cell therapies. Geron's then recently appointed Chief Executive Officer, who apparently had a different set of priorities than his predecessor, indicated that the company had decided to focus on its novel cancer therapies which were further along in development [8]. Geron eventually sold its stem cell research and intellectual property to Asterias Biotherapeutics (CA, USA), another small California-based biotechnology company. Asterias has also received funding from CIRM, for its Phase I/IIa trial with an expanded number of patients and approval from the US FDA for testing on more types of spinal cord injuries. Asterias has now treated 25 patients with no serious side effects and some encouraging results [5].

Another CIRM grant for a human embryonic stem cell derived therapy went to researchers at the University of Southern California for a Phase I trial with a therapeutic being tested for age-related dry macular degeneration, a popular target for pluripotent stem cell researchers. Two other awards were given to Viacyte, Inc. (CA, USA) for its two trials of therapeutics for Type 1 diabetes. Viacyte is currently testing a human embryonic stem cell derived therapeutic to replace lost beta cells in persons with diabetes. The therapeutic is being administered by inserting it in a small pouch that is transplanted under the patient's skin to protect it from the immune system.

It might be asked why CIRM, which was ostensibly established to promote embryonic stem cell research, has supported so few clinical trials with pluripotent stem cells. My informal discussions with staff of CIRM in June 2018 affirmed that CIRM has been open, even enthusiastic, to funding research and clinical trials with therapies developed from human embryonic stem cells when given the opportunity to do so. Given its resources, CIRM has been able to fund all promising proposals submitted for consideration, and apparently the overwhelming majority of these proposals have been for candidate therapeutics developed from adult stem cells, many of them for cancer therapies. So, the simplest explanation is that CIRM was not given the option of funding additional pluripotent stem cell clinical trials. 
Also Proposition 71 instructs CIRM to make maximum use of resources by giving priority to the stem cell research with the greatest potential for therapies and cures [1]. In the 15 years since Proposition 71 was adopted, there have been promising developments in cancer treatments, gene editing, immunotherapy and gene therapy that were not anticipated in 2004. Many of the 45 other clinical trials receiving CIRM's support incorporate these innovations. As well as using adult stem cells of various types from patients and donors, some of which have been genetically modified, CIRM funded clinical trials also involve antibodies, chimeric antigen receptors (CAR-T therapeutics), a type of cancer immunotherapy, proteins, zinc finger nucleases, an artificial restriction enzyme engineering to target-specific DNA sequences, monoclonal antibodies and drugs designed to either enhance or suppress the activity of cells.

To provide some examples of innovative therapies being evaluated in CIRM supported clinical trials, the University of San Francisco (CA, USA) has a Phase I clinical trial using hematopoietic stem cells from the mother's blood marrow to treat babies in the womb with alpha thalassemia major, a blood disorder that is almost always fatal. BrainStorm Cell Therapeutics (CA, USA) is beginning a Phase III trial using mesenchymal stem cells taken from patients' own bone marrow and modified in the laboratory to boost production of neurotropic factors to support and protect neurons in patients with ALS. The University of California in San Diego is testing the antibody cirmtuzumab to disable a protein and thereby slow the growth of leukemia and make it more vulnerable to anti-cancer drugs. Stanford University (CA, USA) is recruiting patients for a B-cell cancers leukemia trial with CAR-T cell therapy that works by isolating patient's own T-immune cells and then genetically engineering them to recognize a protein on the surface of cancer cells and thereby trigger their destruction. Capricor, Inc. (CA, USA) has completed a Phase II trial for patients with heart disease associated with Duchenne muscular dystrophy using donor cells derived from the heart. The City of Hope (CA, USA) is recruiting patients for a Phase I trial in which zinc finger nucleases modified autologous hematopoietic stem progenitor cells along with escalating doses of busalfan will be applied to patients with HIV/AIDS. Angiocrine Bioscience, Inc. (CA, USA), CIRM's 50th clinical trial award, plans to test genetically engineered cells derived from cord blood to see if it can help alleviate or accelerate recovery from the toxic side effects of chemotherapy in people undergoing treatment for lymphoma and other aggressive cancers of the blood and lymph systems.

\section{Reflections}

What does the profile of CIRM's first 50 clinical trials reveal about progress in the stem cell field? The profile of CIRM supported clinical trials indicates that the pluripotent stem cell field has developed more slowly than was anticipated by many supporters of Proposition 71 in 2004 who assumed that human embryonic stem cell research would quickly lead to the discovery of new therapies. Unfortunately, the publicity surrounding the pluripotent stem cells has often exaggerated positive claims and minimized the difficulties of translating pluripotent stem cells into therapies. The slow progress of gene therapy development should have provided a caution. Between 1989 and 2015, 2335 gene therapy clinical trials were completed, ongoing or being initiated worldwide, but it was not until 2012 that the first-gene therapy was approved in the EU and 2017 that the FDA approved a gene therapy for use in the USA [9,10]. Human embryonic stem cells were first derived in 1998 and human induced pluripotent stem cells initially discovered in 2007. The first clinical trial with human embryonic stem cells began in 2009. Therefore, the small number of pluripotent-based candidate therapies available in California is not surprising. However, this is likely to change in the near future.

The good news is that progress in bringing pluripotent stem cell-based therapeutics into clinical trials is being made both in California and elsewhere. A 2018 analysis of recent trends of clinical trials based on human pluripotent stem cells documented 29 such trials with therapeutics derived from human embryonic stem cells taking place in France, China, Brazil, Israel, Brazil, the UK, Canada, Korea and the USA. It also identified three clinical trials based on human induced pluripotent stem cells that were being conducted in Japan, Australia and the UK [11]. Additional trials with pluripotent stem cells have begun in the past year, several of which use induced pluripotent stem cells including trials in Japan for a variety of applications and a trial at UC San Diego Health utilizing induced pluripotent stem cells for colon cancer therapy [12]. Japan, which has a conditional approval scheme for regenerative medicine products, has accorded one induced stem cell treatment product conditional approval [13].

Analysis of all active CIRM grants as of June 2019 from the listing on its website [6] indicates that CIRM has many pluripotent stem cell research projects in its pipeline. CIRM divides its funding categories into several categories depending on the stage of development. Of the inception discovery stage projects CIRM funded in January 2019, nine were using adult stem cells, nine were employing induced pluripotent stem cells, three were 
exploring therapies with human embryonic stem cells, one project involved direct programming, and the approach of one research team was to combine human embryonic stem cells and induced pluripotent stems. Added together, 13 of the 23 projects in the inception discovery stage were exploring potential therapies developed from pluripotent stem cells.

The next stage of research advancement, the quest discovery stage, had a similar profile. Eight of the grants utilized some form of adult stem cell, but there were a greater number of projects exploring applications of pluripotent stem cells. In this category there were eight proposed therapies derived from human embryonic stem cells. Another seven sponsors were exploring candidate therapies from induced pluripotent stem cells while three combined the two types of pluripotent stem cells. The other quest discovery stage initiatives were investigating the application of monoclonal antibodies, encapsulated enriched beta clusters, nanoparticles and direct programming.

CIRM-supported therapeutic translation research projects were equally divided between those using adult stem cells and pluripotent stem cells. The figures were four adult stem cell projects, two initiatives derived from human embryonic stem cell and two utilizing human induced pluripotent stem cells.

Late stage preclinical projects presumably on the threshold of seeking FDA approval were similarly equally divided between adult and pluripotent stem cell projects. Here, the figures were two applications of adult stem cells and one each of human embryonic stem cells and human induced pluripotent stem cells.

\section{Conclusion}

Now 15 years after the adoption of Proposition 71 CIRM is getting ready to ask the people of California for another US $\$ 5$ billion to support the development of the stem cell field. If CIRM receives a second round of funding from the voters of California in 2020, it will be well placed to continue its leadership role in the stem cell field. Moreover, it will be able to play a central role in bringing a series of pluripotent-based stem cell therapies through the clinical trial process and hopefully for at least some of them to receive FDA approval.

\section{Financial \& competing interests disclosure}

The author has no relevant affiliations or financial involvement with any organization or entity with a financial interest in or financial conflict with the subject matter or materials discussed in the manuscript. This includes employment, consultancies, honoraria, stock ownership or options, expert testimony, grants or patents received or pending, or royalties.

No writing assistance was utilized in the production of this manuscript.

\section{References}

1. California Institute of Regenerative Medicine. Text of Proposed Laws: Proposition

71. https://www.cirm.ca.gov/sites/default/files/files/about_cirm/prop71.pdf

2. CIRM. Funding clinical trials. https://www.cirm.ca.gov/clinical-trials

3. CIRM. 2018 annual report: something better than hope. https:/www.cirm.ca.gov/about-cirm/cirm-annual-reports

4. Trounson A, DeWitt N, Feigal EG. The alpha stem cell clinic: a model for evaluating and delivering stem cell-based therapies. Stem Cells Transl. Med. 1(1), 9-14 (2012).

5. McCormack K. Stem cell agency board approves 50th clinical trial. The Stem Cellar. https://blog.cirm.ca.gov/2018/12/13/stem-cell-agency-board-approves-50th-clinical-trial

6. CIRM. All active CIRM grants. https://www.cirm.ca.gov/grants

7. CIRM. Beyond CIRM 2.0 - proposed strategic plan: $2016 \&$ beyond. https:/www.cirm.ca.gov/sites/default/files/files/agenda/151217_Agenda_7_CIRM_StratPlan_final_120815.pdf

8. Chapman AR, Scala CC. Evaluating the first-in-human clinical trial of human embryonic stem cell-based therapy. Kennedy Inst. Ethics J. 22(3), 243-261 (2012).

9. Hanna E, Rémuzab C, Auquier P, Toumi M. Gene therapies development: slow progress and promising prospect. J. Mark. Access Health Policy 5(1), 1265293 (2017).

10. US Food \& Drug Administration. FDA approval brings first gene therapy to the United States (2017). https://www.fda.gov/news-events/press-announcements/fda-approval-brings-first-gene-therapy-united-states

11. Guhr A, Kobold S, Seltmann S, Seiler Wukczyn AEM, Kurtz A, Löser P. Recent trends in research with human pluripotent stem cells: impact of research and use of cell lines in experimental research and clinical trials. Stem Cell Reports 11(2), 485-496 (2018).

12. Villa Y. First patient treated for colon cander using reprogrammed adult cells. The Stem Cellar (2019). https://blog.cirm.ca.gov/2019/04/10/first-patient-treated-for-colon-cancer-using-reprogrammed-adult-cells/

13. Sipp D, Munsie M, Sugarman J. Emerging stem cell ethics. Science 360(6395), 1275 (2018). 